\title{
Treatment of one case of cerebral palsy combined with posterior visual pathway injury using autologous bone marrow mesenchymal stem cells
}

Min $\mathrm{Li}^{1}$, Aixue Yu ${ }^{1}$, Fangfang Zhang ${ }^{1}$, GuangHui Dai ${ }^{1}$, Hongbin Cheng ${ }^{1}$, Xiaodong Wang ${ }^{1}$ and Yihua An ${ }^{1,2^{*}}$

\begin{abstract}
Background: Cerebral palsy is currently one of the major diseases that cause severe paralysis of the nervous system in children; approximately 9-30\% of cerebral palsy patients are also visually impaired, for which no effective treatment is available. Bone marrow mesenchymal stem cells (BMSCs) have very strong self-renewal, proliferation, and pluripotent differentiation potentials. Therefore, autologous BMSC transplantation has become a novel method for treating cerebral palsy.
\end{abstract}

Methods: An 11-year-old boy had a clear history of dystocia and asphyxia after birth; at the age of 6 months, the family members observed that his gaze roamed and noted that he displayed a lack of attention. A brain MRI examination at the age of 7 years showed that the child had cerebral palsy with visual impairment (i.e., posterior visual pathway injury). The patient was hospitalized for 20 days and was given four infusions of intravenous autologous BMSCs. Before transplantation and 1, 6, and 12 months after transplantation, a visual evoked potential test, an electrocardiogram, routine blood tests, and liver and kidney function tests were performed.

Results: The patient did not have any adverse reactions during hospitalization or postoperative follow-up. After discharge, the patient could walk more smoothly than he could before transplantation; furthermore, his vision significantly improved 6 months after transplantation, which was also supported by the electrophysiological examinations.

Conclusions: The clinical application of BMSCs is effective for improving vision in a patient with cerebral palsy combined with visual impairment.

\section{Background}

This case study represents a typical case of cerebral palsy combined with visual impairment. With medical advances, the active treatment of preterm infants, children with dystocia, and children with encephalitis or hypoxic-ischemic encephalopathy results in significant increases in the survival rates of these patients; however, compared to normal infants, these patients have significantly increased incidences of periventricular white matter demyelination. Many regions of the brain play

\footnotetext{
* Correspondence: riveran@163.com

'Department of stem cell transplantation, General Hospital of Chinese People's Armed Police Forces, Beijing 100039, China

${ }^{2}$ Beijing Neurosurgical Institute, Beijing Tiantan Hospital, Capital Medical University, Beijing 100050, China
}

(C) 2012 Li et al.; licensee BioMed Central Ltd. This is an Open Access article distributed under the terms of the Creative Commons Attribution License (http://creativecommons.org/licenses/by/2.0), which permits unrestricted use, distribution, and reproduction in any medium, provided the original work is properly cited. important roles in the generation of vision, such as the cerebral cortex, the white matter, and the basal ganglia [1-3]. During the perinatal period, most cerebral palsy patients have a history of intrauterine hypoxia, preterm birth, dystocia, asphyxia after birth, kernicterus, or other complications. These factors can all result in impaired function of the visual areas of the brain, which currently has no effective treatment.

\section{Methods}

\section{Ethics}

Prior to stem cell therapy, a consent form was signed by the guardians of the patient. This study was approved by the ethics committee of our hospital.

\section{Biomed Central}




\section{General patient information General information}

The patient, an 11-year-old boy, was admitted to our hospital mainly due to "binocular vision disorders that had lasted more than 11 years". The patient was born full-term with dystocia and had a history of significant asphyxia, which improved after symptomatic treatment. At the age of 6 months, his family members found that he had trouble concentrating and following objects as well as easy irritability and hyperactivity. A brain MRI performed at the age of 7 showed cerebral hypoplasia and optic nerve atrophy. The diagnosis was cerebral palsy with visual impairment. He could not see and had no light perception before he was 8 years old. At the age of 8 , the patient started to have light perception, and he could only see objects $20 \mathrm{~cm}$ in front of him at the age of 9; after that, his vision did not improve. When admitted to our hospital, the physical examination revealed that the patient presented with stuttering, a right-eye visual acuity of $30 \mathrm{~cm}$, and a left-eye visual acuity of 20 $\mathrm{cm}$. The pupils were equal and round with diameters of $3 \mathrm{~mm}$; the eyes were sensitive to light reflection, the movements of both eyes were normal, strabismus was absent, horizontal nystagmus was present, and eye closure was effective. The bilateral finger muscle strength was grade 4, the right lower limb muscle tension was grade 1 , the tendon reflexes were active, and the bilateral Chaddock's sign was $(+)$.

\section{Auxiliary examination}

A brain MRI examination revealed bilateral parietaloccipital lobe and corpus callosum dysplasia (Figure 1).

Ocular fundus examination: A leopard-spot-like fundus was observed, the boundary of the optic disc was clear, the color of the temporal disc border was light, the
C/D was 0.5-0.6 (normal cup to disc ratio: $<0.3$ ), and the fovea reflex was $(-)$.

\section{Visual evoked potential (VEP) (2010-10-22)}

Flash stimulation tests were performed on both eyes. The results revealed that the waveforms of both eyes were poorly differentiated, the fundus was slightly wider than normal, and the P100 latency was basically normal (Figure 2).

\section{Intervention measures}

\section{Stem cell source}

Bone marrow was collected from the patient. All tests were normal, including blood leukocytes; lymphocytes; liver function (aspartate aminotransferase, alanine aminotransferase, alkaline phosphatase, lactate dehydrogenase, and hydroxybutyrate dehydrogenase); renal function (uric acid, creatinine, $\beta 2$-microglobulin, and $\alpha 1$ microglobulin); blood sugar; and blood lipids. The patient did not have syphilis, HIV, hepatitis B, or hepatitis C infection, and there was no history of familial or hereditary diseases.

\section{BMSC culture}

Bone marrow was collected from the posterior superior iliac spine. Sixty microliters of bone marrow was extracted, and mononuclear cells in the bone marrow were separated using density gradient centrifugation. Cells were then inoculated into $100 \mathrm{ml}$ flasks at a concentration of $3 \times 10^{5}$ cells $/ \mathrm{ml}$ in $\alpha$-MEM containing $10 \%$ FBS. Cells were passaged when the cell density was above $90 \%$. Cells were collected at the 5 th generation and were used for transplantation by intravenous infusion.

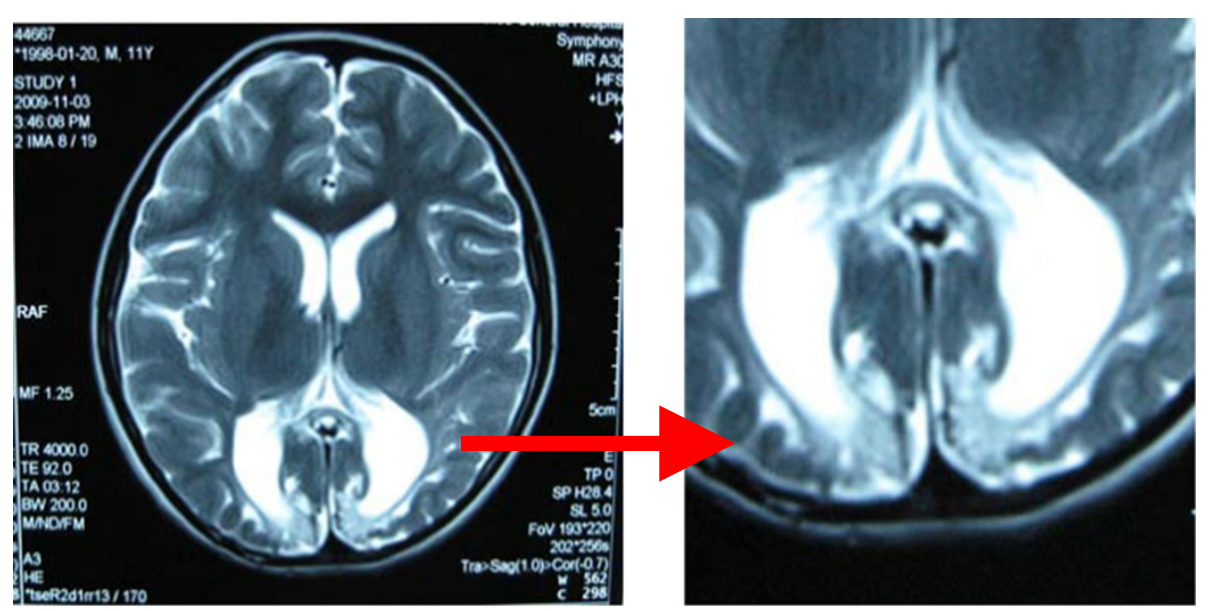

Figure 1 Brain MRI showed the bilateral parietal-occipital lobe and corpus callosum dysplasia. 


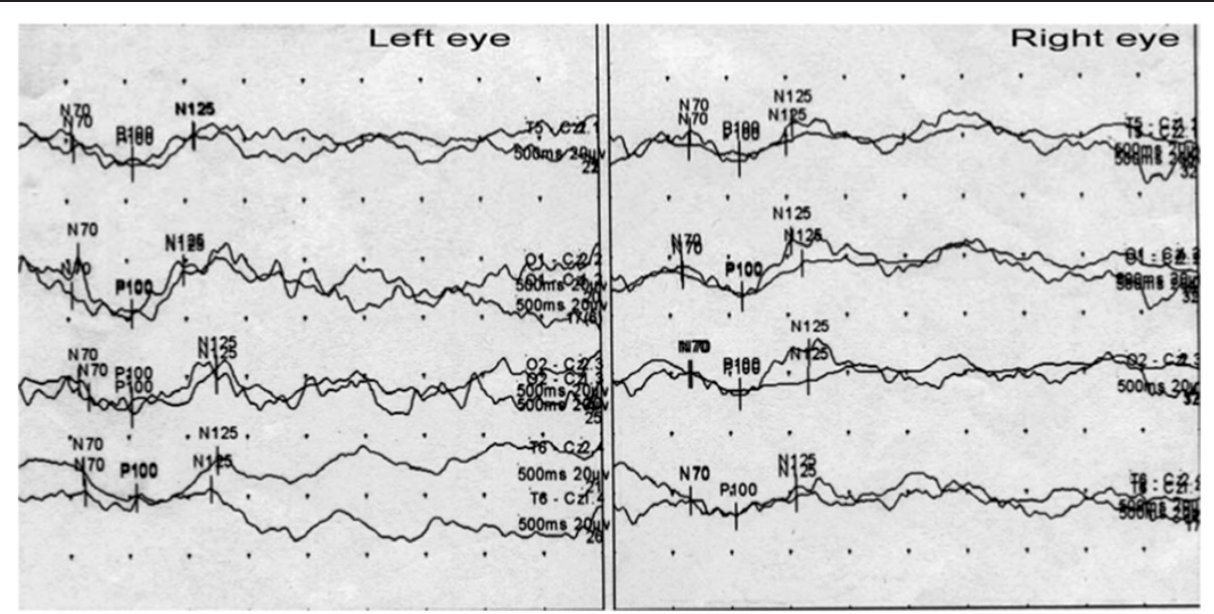

Figure 2 Visual evoked potential on Oct. 22, 2010: Flash stimulation tests were performed on both eyes. The results revealed that the waveforms of both eyes were poorly differentiated, the fundus was slightly wider than normal; P100 amplitude was lower than normal (T6- CZ), but the P100 latency was basically normal.

\section{The BMSC quality standard}

Prior to clinical application, multiple tests were performed on the stem cells, including (1) cell morphology, (2) cell surface marker detection, (3) bacterial detection, (4) mycoplasma detection, and (5) endotoxin detection.

\section{Clinical session of treatment}

At each treatment session, the stem cells were fully dispersed and mixed using $100 \mathrm{ml}$ normal saline, and then $4 \times 10^{7}$ cells were intravenously infused. Four infusions were performed in each session, and the interval between two infusions was 7 days. After each time infusion, the patient was monitored for vital signs including blood pressure, heart rate, blood oxygen, and respiration over 24 hours. Immunosuppressants were not administered throughout the treatment period.

\section{Monitoring of the clinical response in the patient}

Blood leukocytes, lymphocytes, liver function, and kidney function were monitored before transplantation and $1,3,6$, and 12 months following.

\section{Results}

\section{Detection of BMSC quality}

(1) Cell morphology-The cells showed typical BMSC morphology and strong growth under a phase-contrast microscope. (2) Cell surface marker detection: CD44 and CD29 positive rates were greater than 95\%; the CD106 positive rate was greater than $80 \%$; and the CD34, CD45, CD14, and HLA-DR expression rates were less than 5\% (Figure 3). (3) Bacterial detection was negative. (4) Mycoplasma was negative. (5) Endotoxin results were negative as determined using limulus reagents (according to the bacterial endotoxin and bacterial endotoxin application guidelines of Chinese Pharmacopoeia, 2000 edition).
Monitoring of adverse reactions after transplantation

After one session of stem cell transplantation and at 1 , 3,6 , and 12 months after transplantation, the patient did not have any side effects or complications; all test results were within normal limits, and all vital signs were stable. A physical examination 1 year after transplantation (2011-10-12) revealed that the patient had a right-eye visual acuity of $1 \mathrm{~m}$ and a left-eye visual acuity of $80 \mathrm{~cm}$. The right lower limb muscle tension was significantly decreased compared to that before transplantation, and the patient had heel contact with the ground and walked more smoothly than before transplantation. The auxiliary examinations were performed 1 year after transplantation (2011-10-12); the VEP results showed that the waveforms of both eyes were well differentiated, the fundus was slightly wider, and the P100 latency was essentially normal when flash stimulation tests were performed on both eyes (Figure 4).

\section{Conclusion}

The classic visual pathway contains two parts. The first part is the anterior visual pathway, which refers to the visual pathways below the lateral geniculate nucleus, including receptors, bipolar cells, ganglion cells, the optic nerve, the optic chiasm, the optic tract, and the lateral geniculate body. The second part is the posterior visual pathway, which refers to the visual pathway posterior to the lateral geniculate body, including the optic radiation, the subcortical area, and the visual cortex. The patient in this study had a posterior visual pathway injury, which was based on (1) normal pupillary light reflex; (2) fundus examination, which showed no obvious optic atrophy; (3) eye examination, which showed no positive signs; (4) VEP after flash stimulation of both eyes, which showed poor bilateral waveform differentiation and a 


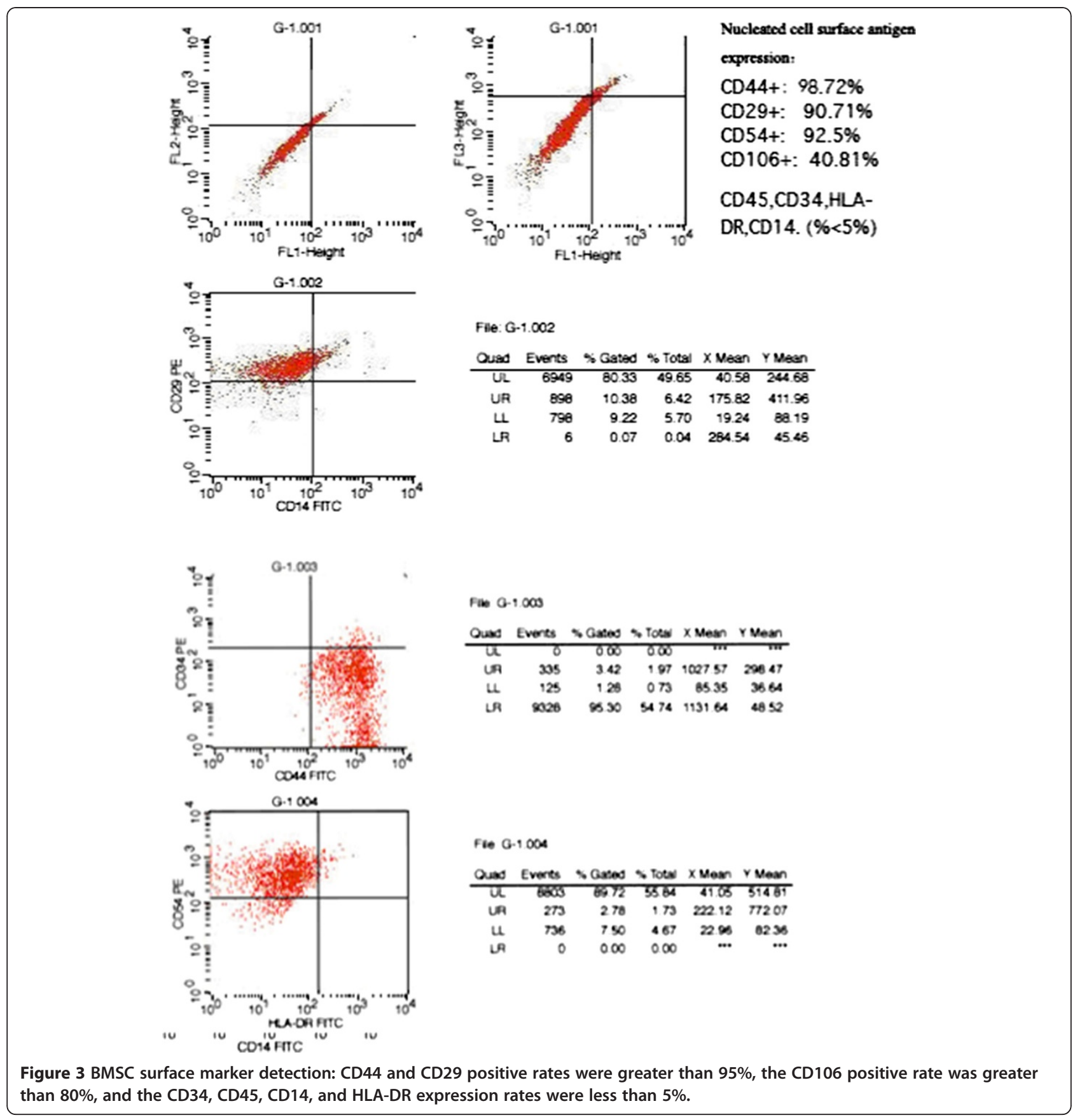

wider fundus; and (5) a brain MRI, which showed hypoplasia of the bilateral parietal-occipital lobe and the corpus callosum. Posterior visual pathway injuries are commonly observed in cerebral contusions of the occipital lobe and in diffused brain injuries, such as brain edemas and hernias; these injuries are usually accompanied by signs of nervous system damage. In addition to visual injuries, this patient had limb movement disorders.

BMSCs have very strong self-renewal, proliferation, and pluripotent differentiation capabilities. Under different induction conditions, BMSCs can differentiate into many types of cells in vitro, such as bone cells, cartilage cells, fat cells, tendons, and muscle cells. BMSCs have many advantages; they are easy to obtain and amplify in vitro, are unlikely to cause immune rejection after transplantation in vivo, and present no ethical controversy. Recent studies have also indicated that BMSCs can be induced into neuron-like cells and glial cells both in vivo and in vitro [4-6] and can differentiate into visual receptors and glial cells in the ganglion $[7,8]$. Many studies have evaluated the treatment of cerebral infarctions [9] and traumatic brain injuries using BMSCs; however, 


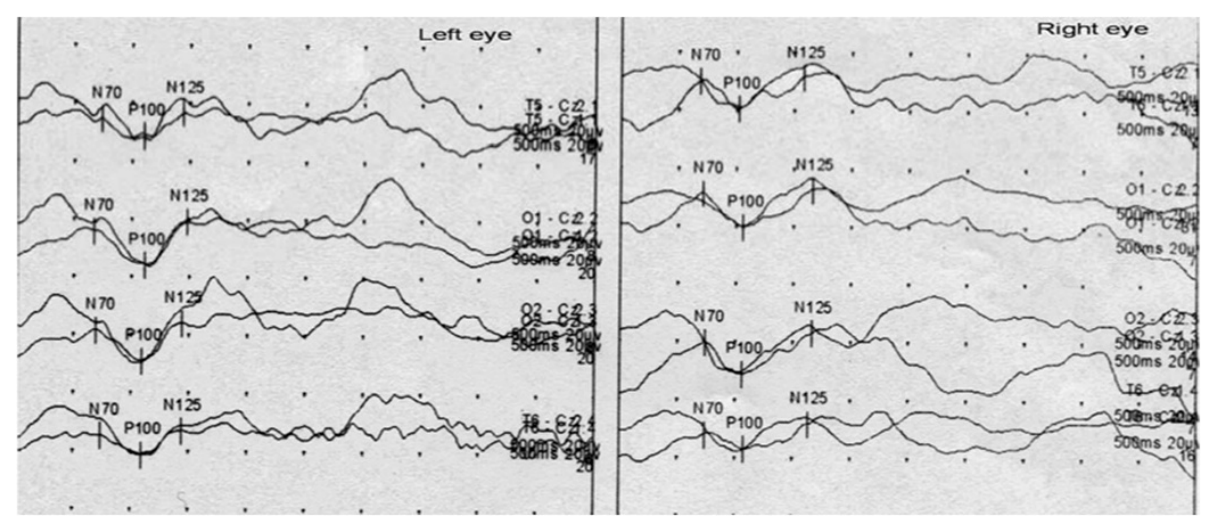

Figure 4 Visual evoked potential on Oct. 12, 2011: Flash stimulation tests were performed on both eyes. The VEP results showed that the waveforms of both eyes were well differentiated, the fundus was slightly wider, P100 amplitude increased obviously and the P100 latency was essentially normal.

studies on hypoxic-ischemic encephalopathy have just begun. In some studies, BMSCs were intravenously transplanted into newborn rats with hypoxic-ischemic encephalopathy; the characteristics of transplanted stem cells could be detected in rat brains, indicating that stem cells can pass through the blood-brain barrier. In addition, these cells can survive at the sites of injury. The specific mechanism may involve several factors. First, the process of stem cells passing through the blood-brain barrier may be a specific transfer process mediated by endothelial cell adhesion molecules in the blood-brain barrier [10]. Second, after brain tissue injury, the blood-brain barrier is damaged, thus increasing permeability [11]. Third, injured tissues possess chemotaxis functions [12]. Finally, cerebral ischemia can induce the expression of neurotrophic factors around the ischemic zone, which is favorable for cell survival [13].

In this study, the characteristics of surface antigens on cultured stem cells were detected using flow cytometry. The results showed that the expression levels of CD44, CD29, CD54, and CD106 were high in nuclear cells (with expression rates of $98.72 \%, 90.71 \%, 92.5 \%$, and $40.81 \%$, respectively). In contrast, the cells were negative for CD45, CD34, HLA-DR, and CD14 expression $(<5 \%$ expression). In BMSC studies, CD9, CD29, CD44, CD71, CD90, and CD106 are recognized as important surface markers of BMSCs, while the hematopoietic stem cell marker antigen $\mathrm{CD} 3$, the leukocyte marker antigen $\mathrm{CD} 45$, and the monocyte/macrophage surface antigen CD14 are not expressed [14,15]. CD45 is an important surface marker of MSCs [16]; it can mediate cell-cell and cell-extracellular matrix interactions and participate in the growth, maturation, and differentiation of MSCs. $\mathrm{CD} 44$ regulates the differentiation, fusion, and migrationspecific adhesion of MSCs, thus providing anchoragedependent growth sites for CD44-expressing MSCs. The cultured stem cells in this study were MSCs.
The mechanism underlying the function of stem cell transplantation in nerve repair is still not very clear. There are two general hypotheses: cell replacement function and neurotrophic effect. Therefore, many researchers are trying different methods to induce the differentiation of BMSCs into essential neuron-like cells for transplantation; they believe that this strategy could enable the transplanted stem cells to fully replace the damaged cells; however, from the viewpoint of neurotrophic hypothesis, pure neuron-like cells might not maximally perform the required function. We believe that the transplanted cells should not be too pure; they should consist of a mixture of a few cell types. Some cells could perform nerve repair through cell replacement, while other cells could secrete different cytokines to assist in nerve repair and regeneration, thus supporting the growth of neural stem cells and inducing differentiation [17]. Therefore, we used BMSCs without inducing any specific differentiation and performed the transplantation using intravenous fusion, which is a safe and simple method.

One year after receiving one session of BMSC transplantation, the patient described in this study showed significant improvement based on his symptoms, physical examinations, and electrophysiological studies. The physical examination results revealed that the right-eye visual acuity was $100 \mathrm{~cm}$ and the left-eye visual acuity was $80 \mathrm{~cm}$. The right lower limb muscle tension was significantly decreased compared to the pre-surgical measurement, and the patient walked more smoothly than previously; the VEP was close to normal. During the treatment and at regular follow-ups at 3, 6, and 12 months post-transplant, the patient did not exhibit fever, headache, blood pressure fluctuations, arrhythmias, or other symptoms of discomfort without an obvious reason. During the period of stem cell transplantation, the patient did not use any neurotrophic drugs or drugs that 
improved microcirculation; he also did not receive hyperbaric oxygen therapy or participate in functional rehabilitation exercises. Of course, we cannot completely rule out the possibility that the patient self-recovered; however, it is difficult to attribute these improvements to self-recovery, as his vision did not improve significantly in the two years prior to transplantation but improved rapidly within 1 year after stem cell transplantation. Therefore, we have reason to believe that it was stem cell therapy that promoted the recovery of his vision.

The mechanism that BMSCs use to repair the nerve damage may involve the nutritional effect of the neurotrophic factors (such as BDNF and NGF) released by stem cells [18]. Research has shown that BMSCs can improve neurotrophic factor expression, which may be the key to promoting brain function recovery. Rat BMSCs can continuously express NGF and BDNF when they are cultured in vitro to the sixth generation $[19,20]$. In addition, BMSCs can secrete a large amount of useful cell factors, such as BDNF, that can promote B lymphocytes to increase the free calcium ion concentrations in cells and thus improve their immune regulation and resistance [21]. Mahmood [22] used BMSCs to treat rats with brain injury and showed that the concentrations of NGF and BDNF in the treatment group were significantly higher than those in the control group; Additionally, these rats still showed increased BDNF expression 3 months later. Furthermore, the mechanism may also involve the induction of angiogenesis due to the release of vascular endothelial growth factors that is promoted by stem cells, thus improving blood circulation in the injured regions [23], or a microenvironment that is favorable for the regeneration and repair of autologous stem cells provided by exogenous stem cells, thus promoting the proliferation and differentiation of autologous stem cells and repairing injured nerves. Of course, these are only hypotheses; further confirmation through basic experimental studies is needed.

The reason for the improvement in our patient's symptoms 1 year after stem cell transplantation is unclear; it is possible that in addition to the short-lasting effects that occurred via the trophic support of MSCs, these cells exhibited long-lasting effects $[24,25]$. One possible explanation for the therapeutic mechanism of MSCs is that they increase neurogenesis. Preclinical studies have shown the importance of neurogenesis in an animal model of stroke, and transplanted MSCs might enhance this process [26-28]. Stroke-induced neurogenesis was reported to continue for up to 1 year and to occur in aged brains [29]. After several preclinical studies, Zhu et al. [30] treated several patients by applying autologous stem cells. These authors labeled neural stem cells from humans with superparamagnetic iron oxide nanoparticles and tracked these cells using magnetic resonance imaging (MRI). They did not observe a hypointense signal after 7 weeks, and they attributed this result to a dilution of the signal due to cell proliferation. For several reasons, including ethical concerns, it is difficult to observe stem cell survival in the human body. Currently, the only way to judge cell survival is by an improvement in the symptoms of the treated patients.

In summary, BMSC transplantation can be used to effectively treat cerebral palsy combined with visual impairment. To a certain extent, it can improve limb movement disorders and visual impairment caused by posterior visual pathway injury.

\section{Competing interests}

The authors declare that they have no competing interests.

\section{Authors' contributions}

$M L$ carried out the design of the study and drafted the manuscript. AY and FZ carried out the data collection. GD and HC participated in the design of the study. XW participated in the stem cell clinical register. YA conceived of the study, participated in its design and coordination, and helped to draft the manuscript. All authors read and approved the final manuscript.

Received: 19 November 2011 Accepted: 28 March 2012

Published: 18 May 2012

\section{References}

1. Grönqvist S, Flodmark O, Tornqvist K, Edlund G, Hellström A: Association between visual impairment and functional and morphological cerebral abnormalities in full-term children. Acta Ophthalmol 2001, 79:140-146.

2. Dutton GN, Jacobson LK: Cerebral visual impairment in children. Sem Neonatol 2001, 6:477-485.

3. Mercuri E, Atkinson J, Braddick O, Anker S, Cowan F, Rutherford M, Pennock J, Dubowitz L: Basal ganglia damage and impaired visual function in the newborn infant. Arch Dis Child Fetal Neonatal Ed 1997, 77:F111-F114.

4. Woodbury D, Schwarz EJ, Prockop DJ, et al: Adult rat and human bone marrow stromal cells differentiate into neurons. J Neurosci Res 2000, 61:364-370.

5. Woodbury D, Schwarz EJ, Prockop DJ, Black IB: Neurospheres induced from bone marrow stromal cells are multipotent for differentiation into neuron, astrocyte, and oligodendrocyte phenotypes. Biochem Biophys Res Commun 2004, 322:918-922.

6. Mori T, Kiyono T, Imabayashi H, Takeda Y, Tsuchiya K, Miyoshi S, Makino H, Matsumoto K, Saito H, Ogawa S, Sakamoto M, Hata J, Umezawa A: Combination of hTERT and bmi-1, E6, or E7 induces prolongation of the life span of bone marrow stromal cells from an elderly donor without affecting their neurogenic potential. Mol Cell Biol 2005, 25:5183-5195.

7. Tomita M, Adachi Y, Yamada H, Takahashi K, Kiuchi K, Oyaizu H, Ikebukuro K, Kaneda $\mathrm{H}$, Matsumura M, Ikehara S: Bone marrow-derived stem cells can differentiate into retinal cells in injured rat retina. Stem Cells 2002, 20:279-283.

8. Kicic A, Shen WY, Wilson AS, Constable IJ, Robertson T, Rakoczy PE: Differentiation of marrow stromal cells into photoreceptors in the rat eye. J Neurosci 2003, 23:7742-7749.

9. Li Y, Chopp M, Chen J, Wang L, Gautam SC, Xu YX, Zhang Z: Intrastriatal transplantation of bone marrow nonhematopoietic cells improves functional recovery after stroke in adult mice. J Cereb Blood Flow Metab 2000, 20:1311-1319.

10. Guan XQ, Yu JL, Li LQ, Liu GX: Study on mesenchymal stem cells entering the brain through the blood-brian barrier. Zhonghua Er Ke Za Zhi 2004, 42:920-923.

11. Wang L, Li Y, Chen X, Chen J, Gautam SC, Xu Y, Chopp M: MCP-1, MIP, IL-8 and ischemic cerebral tissure enhance the human bone marrow stromal cell migration in interface culture. Hematology 2002, 7:113-117.

12. Dormady SP, Bashayan O, Dougherty R, Zhang XM, Basch RS: Immortalized multipotential mesenchymal cells and the hematopoietic microenvironment. J Hematother Stem Cell Res 2001, 10:125-140. 
13. Abe $K$ : Therapeutic potential of neurotrophic factors and neural stem cells against ischemic brain injury. J Cereb Blood Flow Metab 2000, 20:1393-1408

14. Mahmood A, Lu D, Wang L, Chopp M: Intracerebral transplantation of marrow stromal cells cultured with neurotrophic factors promotes functional recovery in adult rats subjected to traumatic brain injury. I Jeurotrauma 2002, 19:1609-1617.

15. Im Gl, Kim DY, Shin JH, Hyun CW, Cho WH: Repair of cartilage defect in the rabbit with cultured mesenchymal stem cells from bone marrow. J Bone Joint Surg Br 2001, 83:289-294.

16. Terada N, Hamazaki T, Oka M, Hoki M, Mastalerz DM, Nakano Y, Meyer EM, Morel L, Petersen BE, Scott EW: Bone marrow cells adopt the phenotype of other cells by spontaneous cell fusion. Nature 2002, 416:542-545.

17. An YH, Wan H, Zhang ZS, Wang HY, Gao ZX, Sun MZ, Wang ZC: Effect of rat Schwann cell secretion on proliferation and differentiation of human neural stem cells. Biomed Environ Sci 2003, 16:90-94.

18. Li Y, Chen J, Chen XG, Wang L, Gautam SC, Xu YX, Katakowski M, Zhang LJ Lu M, Janakiraman N, Chopp M: Human marrow stromal cell therapy for stroke in rat: neurotrophins and functional recovery. Neurology 2002 59:514-523.

19. Chen X, Li Y, Wang L, Katakowski M, Zhang L, Chen J, Xu Y, Gautam SC, Chopp M: Ischemic rat brain extracts induce human marrow stromal cell growth factor production. Neuropathology 2002, 22:275-279.

20. Ye M, Chen S, Wang X, Qi C, Lu G, Liang L, Xu J: Glial cell line-derived neurotrophic factor in bone marrow stromal cells of rat. Neuroreport 2005, 16:581-584.

21. Zhang J, Li Y, Chen J, Cui Y, Lu M, Elias SB, Mitchell JB, Hammill L, Vanguri P, Chopp M: Human bone marrow stromal cell treatment improves neurological functional recovery in EAE mice. Exp Neural 2005, 195:16-26.

22. Mahmood A, Lu D, Qu C, Goussev A, Chopp M: Long-term recovery after bone marrow stramal cell treatment of traumatic brain injury in rats. J Neurosurg 2006, 104:272-277.

23. Chen J, Zhang ZG, Li Y, Wang L, Xu YX, Gautam SC, Lu M, Zhu Z, Chopp M: Intravenous administration of human bone marrow stromal cells induces angiogenesis in the ischemic boundary zone after stroke in rats. Circ Res 2003, 92:692-699.

24. Shen LH, Li Y, Chen J, Cui Y, Zhang C, Kapke A, Lu M, Savant-Bhonsale S, Chopp M: One-year follow-up after bone marrow stromal cell treatment in middle-aged female rats with stroke. Stroke 2007, 38:2150-2156.

25. Liu Z, Li Y, Zhang X, Savant-Bhonsale S, Chopp M: Contralesional axonal remodeling of the corticospinal system in adult rats after stroke and bone marrow stromal cell treatment. Stroke 2008, 39:2571-2577.

26. Li WY, Choi YJ, Lee PH, Huh K, Kang YM, Kim HS, Ahn YH, Lee G, Bang OY: Mesenchymal stem cells for ischemic stroke: Changes in effects after ex vivo culturing. Cell Transplant 2008, 17:1045-1059.

27. Abrahams JM, Gokhan S, Flamm ES, Mehler MF: De novo neurogenesis and acute stroke: Are exogenous stem cells really necessary?. Neurosurgery 2004, 54:150-156.

28. Lindvall O, Kokaia Z, Martinez-Serrano A: Stem cell therapy for human neurodegenerative disorders-how to make it work. Nat Med 2004, 10(Suppl):42-50.

29. Kokaia Z, Thored P, Arvidsson A, Lindvall O: Regulation of stroke-induced neurogenesis in adult brain-recent scientific progress. Cereb Cortex 2006, 16(Suppl 1):1162-1167.

30. Zhu J, Zhou L, XingWu F: Tracking neural stem cells in patients with brain trauma. N Engl J Med 2006, 355:2376-2378.

doi:10.1186/1479-5876-10-100

Cite this article as: Li et al.: Treatment of one case of cerebral palsy combined with posterior visual pathway injury using autologous bone marrow mesenchymal stem cells. Journal of Translational Medicine 2012 10:100.

\section{Submit your next manuscript to BioMed Central and take full advantage of:}

- Convenient online submission

- Thorough peer review

- No space constraints or color figure charges

- Immediate publication on acceptance

- Inclusion in PubMed, CAS, Scopus and Google Scholar

- Research which is freely available for redistribution 